\title{
Uso de técnicas de geoprocessamento na determinação de áreas de risco de incêndio e determinação de locais para a instalação de torres de observação de incêndios. Estudo de caso: Floresta Nacional de São Francisco de Paula/RS
}

Daiane Soares Caporal

VANDERLEI DECIAN

Pedro Roberto Madruga

\section{Resumo}

Neste trabalho, as ferramentas do geoprocessamento foram utilizadas com o objetivo de elaborar um mapa de risco de incêndios para a Floresta Nacional de São Francisco de Paula/RS e determinar os locais mais adequados para a localização estratégica de duas torres de observação de incêndios, que auxiliem na prevenção e combate de incêndios na floresta. O mapeamento de risco de incêndios foi realizado seguindo-se basicamente a metodologia proposta por Vettorazzi \& Ferraz (1998). Assim, utilizando-se a imagem do satélite Ikonos // e cartas topográficas correspondentes à área de estudo, bem como com a realização de trabalhos de campo, foi possível gerar, por meio de interpretação visual, no software Idrisi for Windows (versão 32 bits), 6 Planos de Informação, os quais foram integrados através de SIG, dando lugar a um mapa de risco de incêndio da zona. Este mapa de risco, aliado às demais informações referentes ao terreno e aos costumes locais, permitiram determinar os melhores pontos para a instalação das torres. Concluiu-se que a metodologia proposta adequou-se a área em estudo, e que a zona necessita de um plano estratégico de prevenção e combate a incêndios visto a sua importância como área de preservação e devido a seu histórico de ocorrência de incêndios.

Palavras-chave: Florestas Nacionais, geoprocessamento, incêndios florestais. 


\section{Summary}

In this work, the tools of geoprocessing were used as a subject to elaborate a map of fires risk to the National Forest of São Francisco de Paula, State of Rio Grande do Sul, and also to determinate suitable spots for strategic location of two fire observation towers, that could help for the prevention and combats to fires in the forest. Mapping fire risk was achieved by following, basically, the methodology proposed by Vettorazzi \& Ferraz (1998). In this way, using the image of the satellite Ikonos /I and topographical maps that corresponded to the study area, such as realizing practice works, it was possible to generate, at the software Idrisi for Windows (32 bits), 6 layers, which were integrated using GIS, giving place to a map of fires risk to the zone. This map, associated with other information about the zone and of the local habits, allowed the determination of the spots to installate the towers. It was ended that the proposed methodology adapted to the study area, and that the zone needs a strategic plan of prevention and combats to fires because of its importance as a preservation area and due to its report of fires occurrence.

Keywords: National Forests, geoprocessing, forests fires.

\section{Introdução}

Nas últimas décadas temos visto crescer a preocupação das sociedades com a preservação do meio ambiente. Inúmeros países, como o nosso, passaram a responder positivamente estabelecendo formas de preservação dos remanescentes florestais e estratégias para a exploração sustentável das florestas, entre as quais se destaca a criação de Unidades de Conservação como é o caso da Floresta Nacional de São Francisco de Paula. Entretanto, para assegurar a preservação destas áreas, é necessário que elas sejam objeto de estudos para verificar os prováveis riscos a que estão sujeitas e propor medidas capazes de evitar danos às mesmas.

Este trabalho se propôs a realização do mapeamento de risco de incêndios, distinguindo-se três zonas de risco (alto, médio e baixo), bem como a determinação dos melhores locais para a instalação de torres de observação de incêndio na área da Flona estudada. Para atingir tais objetivos, foram usadas ferramentas de geoprocessamento, as quais permitiram segurança e precisão na obtenção, processamento e apresentação dos dados, a partir do uso da metodologia proposta por Vettorazzi \& Ferraz (1998), com as de- 
vidas adaptações, conforme sugere o próprio autor.

Os resultados aqui apresentados são de grande importância para orientar a tomada de decisão por parte dos administradores da Flona, podendo contribuir para o planejamento das estratégias de preservação da área e prevenção do risco de incêndio.

\section{Metodologia \\ Área de estudo}

A área objeto deste estudo foi a Floresta Nacional de São Francisco de Paula, localizada no nordeste do estado do Rio Grande do Sul, a $27 \mathrm{Km}$ da cidade de mesmo nome, no Distrito de Rincão dos Kroeff, entre as coordenadas geográficas de $29^{\circ} 23^{\prime}$ a $29^{\circ} 27^{\prime}$ de latitude sul e $50^{\circ} 23^{\prime}$ a $50^{\circ} 25^{\prime}$ de longitude oeste. Fitossociologicamente está localizada, na região da Floresta Ombrófila Mista, onde ocorre a predominância da gimnosperma Araucaria angustifolia, associada a angisopermas dicotiledôneas, sendo por isso, também chamada de Mata de Araucária ou Floresta Mista.

O clima é temperado com invernos rigorosos, registrandose neve em algumas ocasiões e com freqüente ocorrência de geadas e nevoeiros. A temperatura média anual é inferior a $18,5^{\circ} \mathrm{C}$ e a umidade relativa média é de $86 \%$. Na região, predominam ventos norte nos meses de junho, julho e agosto e ventos nordeste nos demais meses do ano, sendo que a velocidade média destes ventos é de, aproximadamente, 3m/s. Com uma área total de 1.600,76 ha, caracteriza-se por um relevo ondulado a fortemente ondulado com recorte profundo de alguns rios, havendo regiões abruptas que originam um relevo relativamente movimentado (IBAMA, disponível em: $<w w w$. ibama.gov.br> e <www.bdt.fat.org.br/ibama/flonas/flona).

Segundo Streck et alli (2002), a Flona de São Francisco de Paula pertence à unidade de mapeamento de solos Bom Jesus, classificado como Cambissolo Húmico alumínico típico (Cha1), apresentando-se em processo de transformação, com o horizonte $A$ húmico e extremamente ácido.

Ao redor da Flona ocorrem áreas agrícolas e florestais, bem como campos nativos, o que juntamente com os fortes ventos predominantes no local, a presença de vegetação variada e relevo movimentado, permitiram a análise do risco de incêndio da Flona de São Francisco de Paula e consequentemente, a proposição dos melhores locais para a instalação de torres de observação de incêndios. 


\section{Obtenção dos Planos de Informação}

Para a análise de risco de incêndio da Floresta Nacional de São Francisco de Paula, foram considerados 6 fatores: uso do solo; sistema viário; declividade do terreno; exposição/insolação e altitude da Flona e uso do solo do seu entorno. Utilizando o Sistema de Informações Geográficas (SIG), estes fatores foram processados, gerando 6 Planos de Informação (P.I.s) que originaram os Mapas Temáticos relativos a fatores de risco de incêndio. Estes mapas foram elaborados a partir do uso de imagem digital do sensor Ikonos II e cartas topográficas que abrangem a área da Floresta Nacional de São Francisco de Paula.

Assim, primeiramente foi feito o reconhecimento da área a partir das cartas da Diretoria de Serviço Geográfico do Exército, $1^{\circ}$ Divisão de Levantamento, em escala 1:50.000, sendo escanerizada a área de estudo contida na carta de Tainhas (SH 22-X-C-II-3). A imagem obtida foi importada para o programa Auto Cad, onde foram digitalizadas as curvas de nível com eqüidistância de 20 metros.

Posteriormente realizou-se a composição das três bandas provenientes do sensor Ikonos II, através dos módulos Image Processing/Enhacement/Composit do Idrisi for Windows, obtendose uma imagem GNB (green, near red, blue), com a qualidade desejada para realizar a interpretação visual.

Logo, em trabalho de campo, foram tomados 49 pontos de controle com o auxílio do GPS topográfico, para o georreferenciamento da imagem e observou-se também o uso do solo para os diferentes talhões da floresta e para a área de entorno da Flona, para que se pudesse, em laboratório, fazer uma interpretação visual em tela, correta e detalhada da imagem do sensor Ikonos II, utilizando-se os parâmetros de textura, cor, tonalidade, forma e padrão.

Os Planos de Informações foram obtidos a partir de aplicativos computacionais como o programa AutoCad 2000 (curvas de nível) e o programa Idrisi for Windows (redes de drenagens, rede viária, usos da terra e toponímias), e posteriormente sobrepostos à imagem georreferenciada. Estes P.I.s receberam diferentes pesos, em função do grau de importância para o risco de incêndio, obtendose assim, os Mapas de Fatores que ao serem cruzados, utilizando Sistemas de Informações Geográficas, resultaram o mapa de risco de incêndio. Quanto maior for o valor estabelecido, maior é a probabilidade de ocorrência de incêndios no local. 


\section{Uso do solo da Flona}

Este plano considerou os diferentes usos do solo no espaço da Floresta Nacional de São Francisco de Paula, já que cada tipologia vegetal representa diferentes condições de risco de ocorrência e propagação de incêndios (Soares, 1996). O mapa de uso do solo foi elaborado a partir da interpretação visual da imagem proveniente do sensor Ikonos II (setembro de 2000) e com base no trabalho de campo realizado. A este P.I. foram inferidos diferentes pesos, variando de 0 a 10, segundo a importância de cada uso do solo para o risco de incêndio, obtendo-se, assim, o primeiro Mapa de Fatores. Os diferentes usos do solo da Flona com o peso relacionado podem ser verificados na Tabela 1.

TABELA 1: Peso adotado para cada uso do solo da Flona.

\begin{tabular}{lcc}
\hline Uso do solo & Combustibilidade do material & Peso \\
\hline Lâmina d'água & Nula & 0 \\
Banhado & Nula & 0 \\
Construções & Média & 6 \\
Floresta Implantada (Araucária) & Média & 6 \\
Floresta implantada (Pinus taeda) & Alta & 10 \\
Floresta Implantada (Pinus elliotti) & Alta & 10 \\
Floresta implantada (Eucalyptus sp.) & Média-alta & 7 \\
Floresta mista (Araucária/Pinus) & Alta & 9 \\
Floresta mista (Araucária/Nativa) & Baixa & 4 \\
Floresta nativa & Baixa & 2 \\
Floresta implantada (Cupressus sp.) & Bédia-alta & 7 \\
Campo nativo & Alta & 10 \\
Clareiras & Baixa & 1 \\
\hline
\end{tabular}




\section{Uso do solo do entorno da Flona}

Considerou apenas o uso do solo nas regiões limítrofes da Flona, em um raio de $500 \mathrm{~m}$ a partir do limite, pois a grande quantidade de campos nativos ao seu redor e as freqüentes queimadas realizadas nestes campos, são um fator de grande importância para desencadear um incêndio na floresta vizinha. Cada ocupação da terra recebeu um valor, também de 0 a 10, segundo o seu grau de influência para o risco de incêndio na Flona. Estes dados estão apresentados na Tabela 2.

TABELA 2: Peso adotado para cada uso do solo do entorno da Flona.

\begin{tabular}{lcc}
\hline \multicolumn{1}{c}{ Uso do solo } & Combustibilidade do material & Peso \\
\hline Pastagens & Baixa & 1 \\
Floresta Implantada (Araucária) & Média & 6 \\
Floresta Implantada (Pinus taeda) & Alta & 10 \\
Floresta Implantada (Pinus elliotti) & Alta & 10 \\
Floresta mista (Araucária/Nativa) & Baixa & 4 \\
Floresta nativa & Baixa & 2 \\
Regeneração natural & Baixa & 3 \\
Campo nativo & Alta & 10 \\
Solo exposto & Baixa & 1 \\
Estradas externas & Média & 5 \\
\hline
\end{tabular}

\section{Declividade}

Segundo Batista (1990), a declividade do terreno influencia negativamente na propagação de incêndios de forma que, quanto maior for a inclinação do terreno, maior será a velocidade de propagação do fogo, gerando zonas de maior risco em caso de incêndios.

Assim, para a elaboração do mapa de fatores de risco de incêndio, primeiramente foi feita a carta clinográfica da Flona através 
da reclassificação das curvas de nível, depois de interpoladas. As curvas de nivel foram digitalizadas no programa AutoCad, editadas no Carta Linx e, logo, exportadas para o Idrisi, onde finalmente foram interpoladas pelo método da Krigagem. A obtenção da carta clinográfica foi feita segundo a metodologia de Vettorazzi \& Ferraz (1998), a qual está especificada na Tabela 3. Logo, o mapa de fatores foi obtido ao estabelecer-se pesos para cada classe de declividade, os quais variam de 4 a 8 .

\begin{tabular}{lc} 
TABELA 3: Classes de declividade e pesos \\
\hline Classes de Declividade (\%) & Peso \\
\hline $5-15$ & 4 \\
$16-25$ & 5 \\
$26-35$ & 6 \\
$36-45$ & 7 \\
acima de 45 & 8 \\
\hline
\end{tabular}

\section{Exposição das vertentes/ insolação}

As vertentes que recebem maior intensidade dos raios solares durante o dia, são mais propícias a darem início a um incêndio na floresta. Assim, o mapa de insolação do terreno foi feito no SIG Idrisi através do módulo Gis analisys/Context operators/Surface/ Analytical Hillshdisng e teve como base o grau de insolação das vertentes na estação do verão, entre as 13 e 15:30 horas, pois neste horário a umidade relativa do ar é menor, a secagem do orvalho sobre as plantas, em geral, já aconteceu e a evapotranspiração também diminui, ocasionando um maior risco de incêndio.

Para a realização deste mapa de insolação, foi utilizada a seguinte seqüência metodológica: elaboração de dois mapas iniciais de níveis de insolação, um para as 13 horas $\left(93,075^{\circ}\right.$ de inclinação solar), e outro para as 15:30 horas $\left(124,1^{\circ}\right.$ de inclinação solar ângulos calculados em função dos horários de nascimento e pôr do sol); sobreposição destes mapas através da operação Overlay do SIG Idrisi e reclassificação, a qual gerou 10 classes ou níveis de 
insolação para a Flona de São Francisco de Paula, desde o valor mínimo, de $35 \%$ até o valor maximo, de $100 \%$ de insolação. Cada classe recebeu um peso que varia de 2 a 10 , conforme a periculosidade de ocorrência de incêndios, o que pode ser observado na Tabela 4.

TABELA 4: Níveis de insolação e pesos adotados

\begin{tabular}{lc}
\hline $\begin{array}{l}\text { Nivel de insolação (\%) } \\
\text { (verão, das 13 às 15 horas) }\end{array}$ & Peso \\
\hline $35-41,5$ & 2 \\
$41,5-48$ & 2 \\
$48-54,5$ & 4 \\
$54,5-61$ & 4 \\
$61-67,5$ & 6 \\
$67,5-74$ & 6 \\
$74-80,5$ & 8 \\
$80,5-87$ & 8 \\
$87-93,5$ & 10 \\
$93,5-100$ & 10 \\
\hline
\end{tabular}

\section{Rede Viária}

Este Plano de Informação levou em consideração que às margens das vias por onde passam pessoas e veículos, a probabilidade de ocorrência de incêndios é maior devido a vários fatores como: incêndios criminosos, incêndios provocados por fósforos ou pontas de cigarros acesas, incêndios provocados por trabalhadores em atividade na floresta, incêndios causados pela prática de pequenas fogueiras e outros incidentes (Batista \& Soares, 1997). Assim, quanto maior for a circulação de pessoas pela estrada, maior é o risco de que ocorra um incêndio.

A elaboração deste mapa teve como princípio a digitalização das estradas internas da Flona, bem como dos aceiros divisores dos talhões, o que foi feito através de interpretação visual e trabalho de 
campo. A digitalização efetuou-se no programa Idrisi, com posterior edição no Carta Linx. No Idrisi, estes vetores foram rasterizados, criando-se um raio de influência para cada tipo de estrada - estradas principais, estradas secundárias e aceiros -, segundo o fluxo de pessoas que por ela passam, o que foi feito através dos módulos Gis Analysis/Distance operators/Buffer. Desta forma, considerou-se que as estradas principais, por onde passa um maior número de pessoas e veículos, têm um raio de influência de 60 metros sobre a floresta; as estradas secundárias, 30 metros e os aceiros, por onde devem passar apenas os funcionários da Flona, um raio de 20 metros (metodologia adaptada de Vetorazzi \& Ferraz, 1998). Os três planos (Tabela 5) foram somados dois a dois no módulo Overlay do Idrisi e logo reclassificados com um valor de 3 a 6 , segundo o risco que supõe para a ocorrência de incêndios.

TABELA 5: Vias de acesso consideradas e respectivos pesos

\begin{tabular}{lllc}
\hline Vias de acesso & $\begin{array}{l}\text { Raio de } \\
\text { Influência }\end{array}$ & Acesso & Peso \\
\hline Estradas principais & $60 \mathrm{~m}$ & Funcionários e visitantes & 6 \\
Estradas secundárias & $40 \mathrm{~m}$ & $\begin{array}{l}\text { Pequeno tráfego de } \\
\text { funcionários/visitantes }\end{array}$ & 4 \\
Aceiros/Carreadores & $20 \mathrm{~m}$ & Apenas funcionários & 3 \\
\hline
\end{tabular}

\section{Altimetria}

Para o caso isolado da Flona, onde a variação de altitude é de apenas $300 \mathrm{~m}$, aproximadamente, considera-se que a medida em que a altitude aumenta, as áreas ficam mais expostas aos raios solares e aos ventos, fazendo com que o risco de incêndio seja maior.

O mapa de altitude foi realizado com base na interpolação digital das curvas de nível previamente digitalizadas e eqüidistantes 20 metros uma da outra. Este processo gerou um plano de informa- 
ção com valores digitais de altimetria ponto a ponto, que posteriormente foi reclassificado para as classes demonstradas na Tabela 6 , as quais receberam pesos variando de 4 a 8 , conforme o risco para a ocorrência de incêndios.

TABELA 6: Pesos adotados para as diferentes altitudes da Flona

\begin{tabular}{cc}
\hline Altitude $(\mathrm{m})$ & Peso \\
\hline $620-700$ & 4 \\
$701-750$ & 4 \\
$751-800$ & 5 \\
$801-850$ & 6 \\
$851-900$ & 7 \\
$901-960$ & 8 \\
\hline
\end{tabular}

\section{Elaboração do mapa de risco}

A elaboração do mapa de risco de incêndio da Flona foi realizada com a utilização de técnicas de geoprocessamento, amplamente estudadas em Câmara \& Medeiros (1996) e Rocha (2000).

Assim, depois de ter gerado os 6 P.I.s e os respectivos Mapas de Fatores, estes foram somados dois a dois no módulo Overlay do SIG Idrisi for Windows 32, através de operações boleanas capazes de integrar em um mapa único os valores digitais expressos em cada um dos Mapas de Fatores. Desta forma, cada pixel deste mapa representou a soma de 6 valores (pesos). Este mapa foi reclassificado, gerando o mapa de risco, com apenas três diferentes áreas representando baixo, médio e alto risco de incêndio.

Após a elaboração deste mapa pôde-se propor os pontos adequados para a possível instalação de torres de observação de incêndios, analisando-se os riscos apresentados e sua espacialização no mapa, além da questão de intervisibilidade entre pontos e superfície. Estes pontos foram determinados a partir da análise das ima- 
gens de altimetria e de risco de incêndio, levando-se em consideração também o acesso aos locais. Estes locais devem ser o mais acessivel possível para facilitar o trabalho do pessoal responsável pela vigilância e combate ao fogo. Desta forma, foram identificados dois pontos adequados para a instalação das torres, os quais estão destacados no mapa de risco de incêndio da Flona (Figura 2) .

\section{Resultados e discussões}

Ao levar em consideração apenas as características climáticas predominantes na Flona de São Francisco de Paula, poderse-ía acreditar que, devido a tais condições de clima, há pouca possibilidade de ocorrência de incêndios. Porém, a predominância de ventos fortes ao longo do ano facilitaria a propagação de eventuais incêndios iniciados nas áreas que margeiam a Flona. Aliado a isso, tem-se na região, a cultura de limpar os campos nativos com "pésde-fogo", o que, segundo o administrador da Flona, já foi motivo para a queima de parte dos reflorestamentos. Esta prática da queima de campo, apesar das restrições legais, continua ocorrendo e é, sem dúvida, um elemento importante a ser examinado quando se pensam estratégias de proteção das unidades de conservação.

Assim, é importante que a floresta esteja protegida e vigiada continuamente, o que será facilitado com a instalação das torres de observação de incêndio em locais adequados, identificados através deste estudo, que fariam parte do conjunto dos equipamentos e das estratégias de prevenção e combate a incêndios na Flona de São Francisco de Paula.

O mapeamento de risco de incêndios envolveu a análise de um conjunto de variáveis do ambiente mapeado, as quais já foram esclarecidas. A utilização das técnicas de geoprocessamento na captura destas variáveis, bem como o seu processamento realizado através de SIG, permitiu a obtenção de um mapa de risco de incêndio de forma simples e rápida, se comparada aos métodos tradicionais de mapeamento, pois integraram por meio de operações matemáticas uma série de fatores responsáveis pelo risco de ocorrência de incêndios e seus diferentes pesos associados.

A Figura 1 mostra, a título de exemplo, um dos P.I.s (uso do solo) que foram elaborados para que se chegasse ao mapa final de risco de incêndio para a Flona de São Francisco de Paula, e a determinação dos melhores locais para a instalação das torres $01 \mathrm{e}$ 02 de observação de incêndios (Figura 2). 


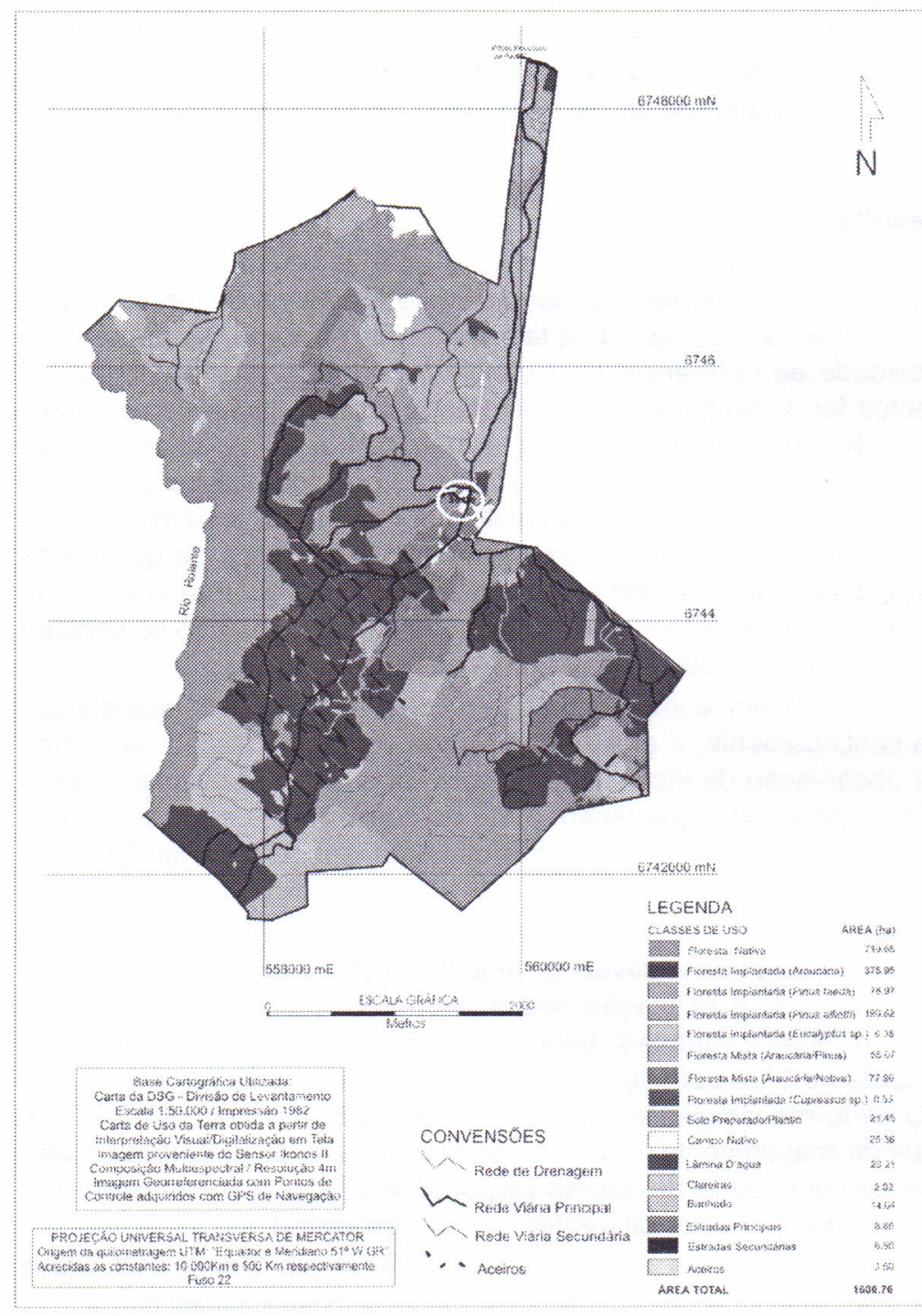

Fig. 1 - Mapa de uso do solo da Flona de São Francisco de Paula. 


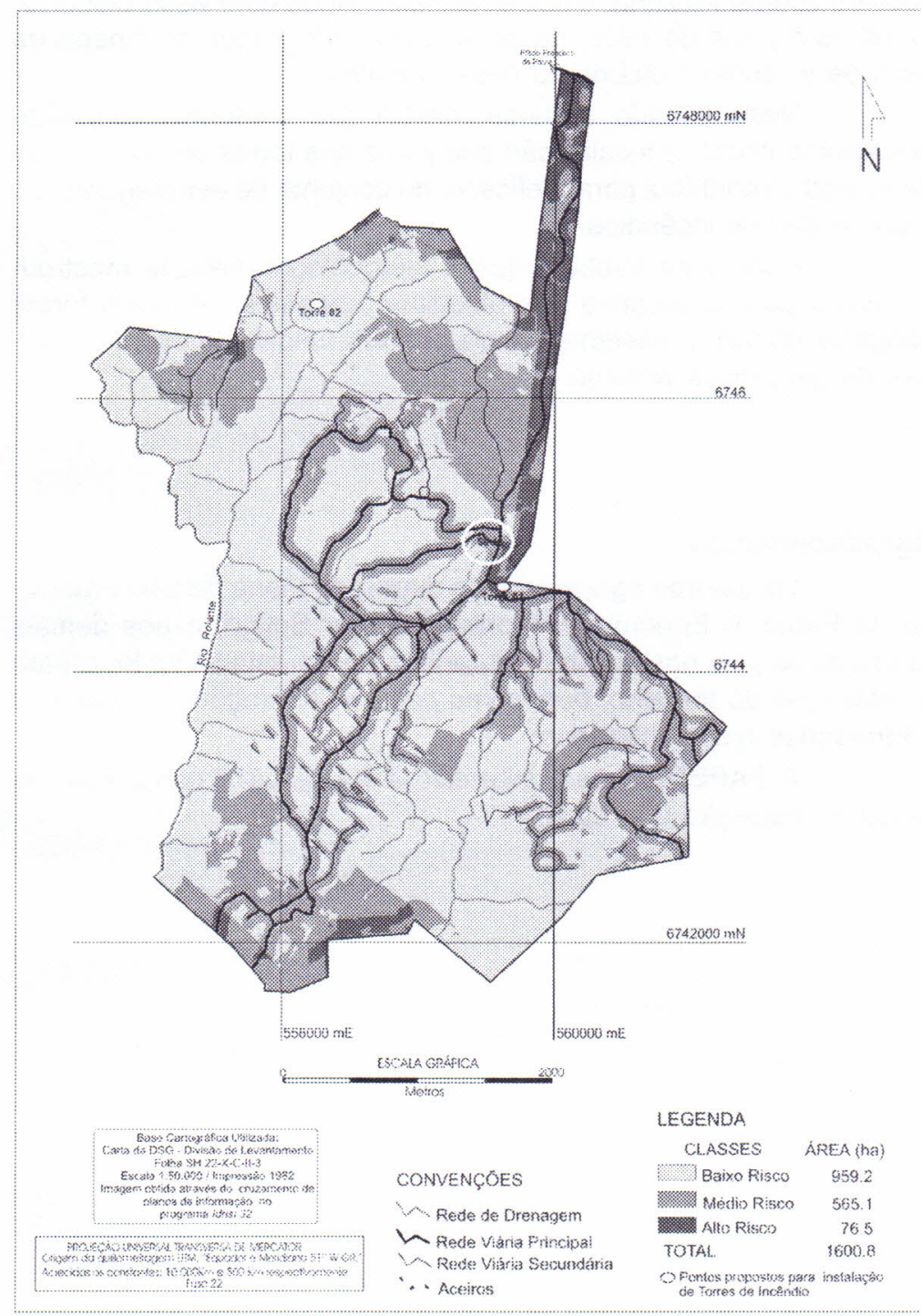

Fig. 2 - Mapa de risco de incêndio da Flona de São Francisco de Paula 


\section{Conclusões}

A importância de vigiar e proteger as Unidades de Conservação do nosso país tais como as Florestas Nacionais, exige que se realize um trabalho de prevenção a possíveis incêndios florestais que possam ocorrer na zona, o que é facilitado tendo uma visão global de todos os fatores de risco, os quais estão integrados no "mapa de risco de incêndios" elaborado neste trabalho.

Neste sentido, pode-se concluir que, conforme os resultados apresentados, a localização adequada das torres de observação de incêndios contribui para a eficácia do conjunto de estratégias para a prevenção de incêndios.

Conclui-se também que a metodologia utilizada mostrouse apropriada ao alcance dos objetivos propostos, os quais foram atingidos de forma bastante satisfatória em função do uso de técnicas de geoprocessamento.

\section{Agradecimentos}

Os autores agradecem ao diretor da Flona de São Francisco de Paula, o Engenheiro Florestal Arthur Soligo, e aos demais funcionários pela hospitalidade durante a nossa estadia no local para a realização do trabalho, bem como pelas colaborações prestadas e informações disponibilizadas.

À FAPERGS pelo incentivo à pesquisa e concessão de Bolsa de Iniciação Científica. 
Referências bibliográficas

BATISTA, A.C. Incêndios Florestais. Imprensa Universitária da Universidade Federal Rural de

Pernambuco, Recife, 1990, 115p.

BATISTA, A.C. \& SOARES, R. V. Manual de Prevenção e Combate a Incêndios Florestais. FUPEF, Curitiba, 1997, 50p.

CAMARA, G. \& MEDEIROS, J. S. Geoprocessamento para Projetos Ambientais. INPE, São José dos Campos, SP. 1996.

ROCHA, C. H. B. Geoprocesamento: Tecnologia Transdisciplinar. Juiz de Fora, Ed. Do Autor, 2000.

SOARES, R. V. Planos de Proteção Contra Incêndios Florestais. In: IV REUNIÃO TÉCNICA CONJUNTA FUPEF/SIF/IPEF E ॥ CURSO DE ATUALIZAÇÃO EM CONTROLE DE INCÊNDIOS FLORESTAIS, 1996, Curitiba. Anais: Curitiba...FUPEF,1996. 163p. p.140-150

STRECK, E.V.; KAMPf, N.; DALMOLIN, R.S.D., KLAMT, E.; NASCIMENTO, P.C.; SCHNEIDER,P. Solos do Rio Grande do Sul. Porto Alegre: EMATER, UFRGS, 2002.

VETTORAZZI, C. A.; FERRAZ, S. F. B. Mapeamento de risco de incêndios florestais por meio de sistemas de informações geográficas (SIG). Scientia Florestalis, n. 53, p. 39-48, 1998.

Sistema Nacional de Unidades de Conservação: bases, princípios e diretrizes. Diretoria de Unidades de Conservação e Vida Silvestre, 1997.

Disponível em <www.ibama.gov.br> Acesso em 03/03/2002

Florestas Nacionais e Reservas Extrativistas. Instituto Brasileiro do Meio Ambiente e dos Recursos Naturais Renováveis, IBAMA. Disponível em: <www.bdt.fat.org.br/ibama/ flonas/flona>. Acesso em: 10/06/2003. 


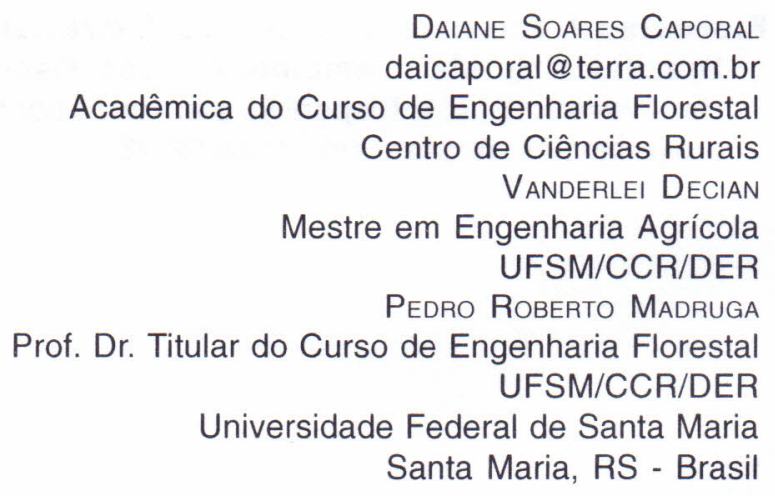

